\title{
PPPs succeeding in tackling neglected diseases
}

Government money sorely needed to sustain success.

\section{Simon Frantz}

Public-private partnerships (PPPs) are fulfilling their promise of producing drugs to treat neglected diseases in developing countries, according to a report from a team at the London School of Economics, UK. But the future of even the most promising initiatives could be threatened by outmoded incentive schemes devised by governments.

The report, entitled The New Landscape of Neglected Disease Drug Development, and funded by the Wellcome Trust, says that the formation of PPPs has been instrumental in the resurgence in $\mathrm{R} \& \mathrm{D}$ activity that has been occurring in the neglected disease area since 2000.

Only 13 new drugs were developed for neglected diseases between 1975 and 1999 - a time when many large pharmaceutical companies left the field. But by the end of 2004, there were 63 neglected-disease drug projects in progress, three-quarters of which are being carried out under the auspices of PPPs, including 18 drugs in trials and two at the registration stage. Even accounting for current attrition rates, 8 or 9 drugs would be expected to be approved over the next 5 years.

All this activity is occurring despite the absence of new government incentives for industry, which shatters the illusion that large companies need commercial incentives to commit to this long-neglected field. "Companies said that long-term business considerations, such as corporate social responsibility and positioning themselves in emerging developing country markets, were more of an influence than returns on their drugs," says Mary Moran, Director of the Pharmaceutical R\&D Policy Project at the London School of Economics, and lead author of the report.

The key to the success of PPPs is that they manage funding and $\mathrm{R} \& \mathrm{D}$ portfolios, giving large companies the freedom to focus on several early-stage research projects, rather than fulfilling the cost burden of more risky, late-stage projects. This shift in emphasis means that companies may enjoy less profits, but limit their overall costs - the so-called 'no-profit, no-loss' model. Between 2000 and 2004, the PPPs took 46 projects through at the relatively miniscule cost of US\$112 million.

Continued success, however, is far from guaranteed. PPPs need funding for the clinical development of products that are moving through the pipeline on a scale that can only be provided by governments. But according to Moran and colleagues, less than a fifth of funding for PPPs has come from public policy funding (see figure), even though several governments have signed up to many of the initiatives.

Governments still seem to be wedded to the belief that large companies favour policies such as transferable intellectual property rights or advanced purchase commitments that commercialize neglected disease markets. "The reality is much different from the perceptions that drive public policy," says Moran.

Commitment from governments is desperately needed, says John Horton, ex-GlaxoSmithKline and now independent consultant working with several PPP projects. "It needs to be made very clear that PPPs are succeeding in their expectations, but to do the job properly they need more funds and, perhaps more importantly, more promise of long-term funds."

Chris Hentschel, CEO of Medicines for Malaria Venture, agrees. "The experiment is succeeding - now we need to take it to the next level and make it sustainable," he says. "If public money doesn't come in this would be a hugely wasted opportunity."

The report also states that there is more of a business case for smaller companies to commit to these initiatives if public policy money is pumped into PPPs. Without the strong marketing and revenue streams that larger companies enjoy, small companies need more commercial incentives to get involved in PPPs.

Tax-relief schemes are only useful when companies have a product that will make a profit, leaving companies with innovative technologies out in the cold. "The biggest incentive would be to pay small companies at close to the market rate for the work that they do," says Hentschel. "PPPs have never had sufficient public money to do that even though they were set up for the purpose of the public good, and every PPP was set up with founders representing the public sector."

The current pipeline of potential products would not exist without philanthropic funding, mainly from the Bill and Melinda Gates Foundation, and now it is time that governments fulfil their side of the bargain. "Those people who threw bricks at the industry a few years ago to get involved need to now lobby governments," says Horton. "They need to say industry is now involved - you are failing in your duty as governments in not doing what the rest of the world is."

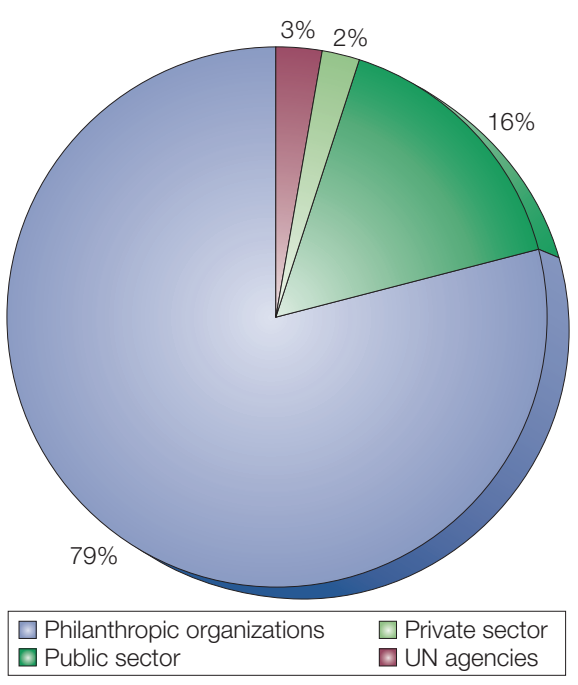

Public sector funding towards PPPs is lagging way behind philanthropic organizations. 